\title{
Integrating Success Scorecards Across Corporate Organizational Levels
}

\author{
Alan C. Maltz ${ }^{*}, 1$, Aaron J. Shenhar ${ }^{2}$, Dov Dvir ${ }^{3}$ and Michael Poli ${ }^{1}$ \\ ${ }^{1}$ Howe School of Technology Management, Stevens Institute of Technology, NJ 07030, USA \\ ${ }^{2}$ Department of Management, Rutgers University, NJ 07102, USA \\ ${ }^{3}$ Department of Management, Ben Gurion University, Israel
}

\begin{abstract}
No organization is sustainable without change, and changes are increasigly introduced through projects. With today's accelerated project-based business environments, corporate success is clearly dependent on the effectiveness of such time-bounded initiatives called projects or programs. As temporary organizations, projects are impacting success both in the short and the long run. This study is thus dedicated to an integrative view of the two distinct levels, corporate and project, from an overall success scorecard standpoint. In particular, we explore the contribution of measuring the human capital and preparing for the future dimensions to overall business success over time. This paper makes the case that an integrated project-based business lifecycle may become a fruitful domain for further investigation, and would go beyond the traditional focus on products and processes only, on one hand and on entire business success, on the other hand.

While multiple dimensions of corporate success have received much attention in recent years, they were often studied separately. Few studies spanned more than one organizational level, while looking at detailed success measures from a very short-term to a very long-term perspective. The dynamic framework developed in this paper includes five integrated dimensions: short-term financial and efficiency measures; benefits to the customer; process effectiveness; human capital management; and preparing (and or creating) the future. This framework may build a basis for organizations to develop specific measures for both the corporate and project levels. Our findings provide implications for management on each dimension, and show how to address the human capital as well creating the future infrastructure required for an organization to build sustainable prosperity in the long run.
\end{abstract}

Keywords: Corporate success, project success, organizational effectiveness, project management, human resources management.

\section{INTRODUCTION - UNDER-EXPLORED DIMENSIONS OF SUCCESS}

Even before the implosion of the stock market in the beginning of the $21^{\text {st }}$ century and the recent global recession, the business community realized that measuring success based on financial values alone is insufficient. Financial scandals, which made headlines when major corporations felt victim to the pressures of 'managing' quarterly results, only emphasized the inadequacy of financial measures such as profit, sales, returns, and even growth.

By now, many have realized that long-term perspectives of organization's effectiveness are crucial. Longer time horizons are particularly important for technology-based firms, operating in rapidly growing markets and fast changing environments. Hamel and Prahalad [1], in their classical book "Competing for the Future" suggested new ways to look at the modern organization that is facing continuous change. They claimed that for survival in the long term, firms must create the future as seen by their potential customers and have the foresight to create and dominate emerging opportunities. They must develop core

*Address correspondence to this author at Stevens Institute of Technology, Wesley J. Howe School of Technology Management, Castle Point on the Hudson, Hoboken, NJ 07030, USA; Tel: 01-561-632-4848;

Fax: 01-775-249-9576; E-mail: alan.maltz@stevens.edu technological competencies, make sure they are preparing the necessary infrastructure, and realize that it may not suffice to compete within the boundaries of existing industries, but rather, they must shape the structure of future industries. When business-related decisions are tested, one could easily see that almost all present successes are the result of decisions taken years ago. And when looking into the future, most of management's strategic decisions will only have an impact on the business, three, five, or even ten years from now.

In our studies on organizational effectiveness, we looked at different data samples spanning multiple time horizons, while addressing separately, the individual project level and the corporate level. We looked at individual projects as cornerstones for creating value for the corporation. Furthermore, as many organizations are increasingly becoming project-driven, a firm's capabilities to leverage its success in project execution; and equally important, its resources allocation between and across projects, have become critical to long-term success.

We have benefited from important concepts such as the Balanced Scorecard [2], yet, we sought to go a step further not only by exploring the lower level of projects, but also pursuing additional critical elements, which may expand the view of what success means at the two organizational levels we studied. Thus our first research objective was to integrate 
studies of organizational success across different organizational levels toward a unified framework consisting of common elements to these levels. The second objective was to study the specific role of the two additional dimensions of the human capital and preparing the future across these levels.

Specifically, our research questions are as follows:

1. How to integrate the study on organizational success may lead to a unified framework with common elements across different organizational levels.

2. What is the role of the human capital dimension and its cross-level impact on organizational success at the project and corporate levels.

3. What is the role the "preparing for the future" dimension for both the project and corporate levels.

We begin by reviewing some current existing frameworks, as well as their limitations, which formed the motivation for this study. We then present our research methodology, followed by presenting the unified framework. The two levels of projects and corporations are then discussed in detail. We conclude with summary of implications and suggestions for further research.

\section{A REVIEW OF ORGANIZATIONAL SUCCESS MEASUREMENTS}

\section{Corporate Success Measures}

Perhaps the most important work in recent years about organizational success measures is the Balanced Scorecard [2]. Kaplan and Norton's assertion is that traditional financial accounting measures (e.g., ROI, EPS) can give misleading signals for continuous improvement and innovation, and are out of step with the skills and competencies needed by today's organizations. The Balanced Scorecard has become an influential multidimensional framework that translates a company's strategy into specific measurable objectives.

The Balanced Scorecard represents a critical step in understanding organizational success, and while it has a substantial impact on strategy formulation and implementation, some limitations and difficulties have been noted. While Kaplan and Norton (1992, 1996, 2000) did provide a "learning and growth" dimension, the broader role of managing the human capital was not specifically discussed. For example, Atkinson et al., [3] suggested that The Balanced Scorecard model was incomplete because it fails to adequately highlight the contributions that employees and suppliers make to help the company achieve its objectives. The argument is that learning is only one part or managing people; other aspects such as motivation, retention, should also be considered Similarly, Smith [4] noted that The Balanced Scorecard fails to account for the role of "motivated employees", a critical issue especially in the service sector. And Edvinsson and Malone [5] suggested that the Balanced Scorecard is only part of what they call the Intellectual Capital of the firm, which consists of the human capital and the structural capital.

While the Balanced Scorecard is widely accepted in a broad range of profit and non-profit organizations; e.g., financial services [6], higher education [7], and health care
[8], during our research interviews, many managers frequently mentioned the lack of a people component in The Balanced Scorecard. For example, Best Foods (now part of Unilever) [9] has been using The Balanced Scorecard for years; however, the company felt it necessary to add a fifth dimension, "People Development" to address this critical issue. Similarly, European firms (e.g., Nokia) have emphasized the importance of human resources management and the way they treat their employees as a critical component to their success. These realizations have prompted companies to include specific assessment of management training, slack time, knowledge worker retention, and issues relating to the company's global employee population. Consequently, these observations have motivated us to look further into the human dimension in assessing organizational success [10].

\section{Project Success Measures}

As project managers and project teams are engaged in day-to-day project execution, they are often not focusing on the business aspects of their project (Williams, 2005). Their attention, rather, is typically operational, and their mindset is on "getting the job done." This mindset may help doing the job efficiently, by not wasting time and money. Yet, it may lead to disappointing business results and even failure when the job was not done effectively. Most project managers have typically seen their job as completed when they finish the project on time, within budget, and to specifications [11]. In some cases, project managers would add the need to please the customer.

This kind of "operational mindset" is often reflected in the traditional project management literature, which has mostly used time, budget, and performance as the indicators for project success. Any of these measures, however, even when taken together, are incomplete and misleading. They may count as successful, projects that met time and budget constraints, but did not meet customer needs and requirement, or projects which ended up having difficulty in the commercialization of the final product. Still, only few studies have suggested adding new elements to the notion of project success - either client satisfaction and customer welfare or business success [12].

As expected, further scholarship introduced the concept of multi-dimensional frameworks for the assessment of project success, which would reflect different interests and different points of view. Pinto and Mantel (1990) for example, identified three aspects of project performance as benchmarks for measuring the success or failure of a project: the implementation process, the perceived value of the project, and client satisfaction with the result. Freeman and Beale [13] identified seven main criteria used to measure project success, among them, technical performance, efficiency of execution, managerial and organizational implications (including customer satisfaction), personal growth, and manufacturer's ability and business performance. And Cooper and Kleinschmidt [14] addressed three dimensions of new product success: financial performance, the creation of new opportunities for new products and markets, and market impact. Finally, Shenhar et al. [15] have incorporated the human capital only as part of their fourth dimension of success - preparing for the 
future (the Success Dimensions Model). With time, however, it became clear that there is a need to look deeper into the role of the human capital in organizational success. This realization has motivated the current work.

\section{METHODS}

\section{Project Level Methodology}

For our work on project success, we chose to perform a two-stage study, which involved a combination of qualitative and quantitative methods and two data sets. The first stage involved a case study research on 15 projects and the second a quantitative study on 127 projects. The fifteen case study projects were part of the larger sample of 127 projects, which seem to add only an insignificant bias to our findings.

All projects we studied were either completed within the recent year, or they were in their last quarter before completion. Data collection was performed in Israel in firms operating in the defense or the commercial market. The projects studied were in a wide variety of industries (e.g., electronics, aerospace, computers, chemical), had significant range in budget (from $\$ 40,000$ to $\$ 2.5 \mathrm{~B}$ ) and in project duration (from 3 months to 12 years).

Israeli industry is closely coupled to Western culture, either in Europe or the US; many of the organizations involved in our study are subsidiaries or partners of American companies, and there is no reason to suspect that the study was biased in any significant way. However, caution should be exercised in generalizing the results of this study, since the sample may not be representative of all projects in general, or in other parts of the world.

Data collection for the first part (case study) was multifaceted, and included in-depth interviews, which were conducted by teams of two or three investigators, and involved at least three people from each project. In addition to project managers, we interviewed members of the project management team, functional team members that were involved in the project, project managers' supervisors, and customer representatives. To strengthen our research validity, and as is often required by qualitative studies, we insisted that investigators interact with their subjects on their own turf, namely at the project site.

Interviews involved open questions on the project mission and objectives, the motivation and the expectations from the project of the different parties involved: the contractor, customer, and user. Data were also obtained on success of the project, as perceived by the different parties, and as compared to their initial expectations. Finally, we obtained data on specific goals and achievements such as meeting time and budget goals, meeting technical and functional requirements, fulfilling customer needs, and achieving business-related results.

The qualitative case data of this study were processed through a method of cross-case comparative analysis, and as required by this method, it was highly iterative, with continuous comparison of data and theory. This method (as described by Eisenhardt, 1989:533), "forces investigators to look beyond initial impressions and see evidence through multiple lenses."
During the case study part of our study, and based on the experience gained in previous studies, we prepared a list of thirteen specific measures to account for the interests of various parties. This list formed the basis for the structured questionnaire, which was used during the quantitative part. During this phase, respondents were asked to rate the importance they place to each of these measures on a sevenpoint assessment scale, from "very low" to "very high." They were also asked to use a seven-point scale to rate the degree of success they perceived in each of these thirteen measures, as well as in a fourteenth measure, assessing the project overall success.

After completing the study on project level success, we decided to explore the same issues at the corporate level. During the exploratory stage of the corporate level research, it became clear that the need for a distinct level to better understand the human capital was missing in all prior studies. The experience gained in the project level study greatly assisted the work at the corporate level. It provided a solid framework onto which to build upon, and a methodology that was proven to be reliable to collect the necessary measures at the corporate level. Both studies employed a qualitative component (field studies, guided interviews) as well as a quantitative method (survey instruments). The survey instruments were designed using Likert scales with proven reliability and construct validity.

\section{Corporate Level Methodology}

In this study we used two complementary methods: a pilot study and a mail survey to provide realism and generalizability. The pilot study included meetings and discussions with senior executives from six companies followed by ten in-depth interviews with members of top management from varying companies. These interviews provided an effective pre-test for a draft of the instrument used in the mail survey that was used to collect empirical data. This process also clarified the specific wording of some measures as well as adding additional measures not found in the literature. It is interesting to note that three of the measures added by the CEOs in the pilot study proved to be important measures as seen by the respondents of the mail survey. These measures were, 'the retention of top employees', 'the quantity and depth of standardized processes', and 'anticipating/preparing for unexpected changes in the external environment'. 'Retention of top employees', which was not found in the literature, emerged as the top measure across all organizational types.

The mail survey consisted of a detailed questionnaire mailed to 1,610 alumni of a major university who were identified as senior managers in their organizations. Several demographic items were collected including industry, typical product life cycle, company revenue, number of employees, markets served and whether the firm was a high-tech organization. The survey listed key measures within each of the five dimensions and asked respondents to select the five most important measures within each dimension. The technique (constant-sum scale) for weighing the 'five most important measures' was similar to the instrument used by Griffin and Page [16] in their study of product development success measures. 
Respondents were also asked to self-rate their firm's performance on the selected 'five most important measures' using an approach modeled after the questionnaire used by Dvir and Shenhar [17] to collect success measures at the Strategic Business Unit (SBU) level. The use of this previously tested method ensures that key variables have construct validity.

\section{The Emergence of a Dynamic Success Measurement Model}

The common motivation behind the debate about success is that management is still struggling with the issue of performance measurement, and is overwhelmed with performance data. In typical real-life situations, management may have difficulty determining which specific measures are critical to the firm, and which measures will influence executives to do the right thing. With this difficulty, many firms keep focusing solely on financial measures and even to this day, most empirical investigations in the field of business strategy have primarily used financial criteria for success -- profitability, return on investment, and revenue.

The continuing struggle to define organizational success was reflected in the Conference Board's concerned report on "New Corporate Performance Measures" [18]. This report discussed the increasing corporate focus on performance, along with the inadequacies of traditional financial measures in the dynamic turbulent environment of today.

The inadequacies of the traditional performance measurement triggered our renewed interest in this subject. We went back and re-looked at our Project level results. We then performed a case study analysis, using our project database and found empirical evidence supporting our assertion that the human side is equally important at the project level as at the corporate level. Based on that study we have updated the project success measurement framework to include the critical role of People in a project's success. We then identified what are the specific dimensions, which are typical to the corporate and project organizational levels, and what time frames are associated with each dimension. The temporal element clearly distinguishes the project and corporate levels, by seeing the project as a 'temporary endeavor'.

Furthermore, as a result of our efforts, the contrast between the project and corporate levels emerged both operationally as well as the need for the appropriate measures of success. Griffin and Page (1996) recognized the need to measure NPD at both project and corporate/program levels. Their approach is different in that they consider that the most appropriate set of measures for assessing project and corporate success depends on the project strategy and the company's business strategy. For example, a company that values being first to market must measure success differently than a company that focuses on maintaining a secure market niche. Rogers and Ghauri [19] found that while measurement at the project level yields great insights and lessons for NPD output success, it is also necessary to move assessment to the 'macro' firm level to obtain an overview of activities. After all, project level success alone, does not guarantee increasing the company's competitiveness.

The initial concept of our corporate model was built on the Balanced Scorecard and Success Dimensions models and examines measures prescribed by five different literature streams. The suggested framework includes five main dimensions: Financial, Market, Process, People Development and Future, and provides an integrative model that seems to address many of the limitations discussed earlier. The five streams of previous research are (1) corporate entrepreneurship, (2) strategy, (3) process and product development, (4) marketing, and (5) economics/ finance. While many individual studies have used a limited number of performance measures, taken together, key publications in each of the five streams show repetitive use of the five dimensions proposed.

What emerged was a dynamic view of organizational success, where different dimensions represent different time horizons. To be successful and sustain it, an organization needs to perform well on all dimensions, but not necessarily at the same time. Meeting short-term goals does not guarantee the future and low performance in financial goals does not necessarily mean failure; often it is a prelude to great success. We therefore called our model the "Dynamic Multidimensional Success Model" or DMDS model, and it will be described in the next sections.

A comparison of our DMDS to the BSC is provided in Fig. (1).

As we can see the learning perspective in the BSC model is now divided into two separate dimensions, human aspect and preparing the future. In our later discussion we will analyze the roles of these dimensions in the two distinct levels of project and corporate. Overall, however, and taken together, the success of most organizations can be divided into five major dimensions, each consisting of several specific measures, often representing different time horizons for both temporary as well as sustained organizations (Longman, 2004, 2011). Furthermore, at both organizational levels we found that the human element is critical at different times - (the shaded areas in Table 1). Similarly, we found that preparing for the future also plays an important role in looking at organizational success. We will thus further discuss these two dimensions in separate sections toward the end of this paper.

Our findings do not mean, nor does this article claim that a single set of measures is universal for all organizations - be it companies, or projects. Rather, it suggests that each organization could use these findings as guidelines, when it attempts to formulize its strategic plans and build its own measures for sustainable success. This is consistent with Otley [20] and Kalagnanam [21] findings that the appropriate set of performance measures is contingent on the particular industry, size, technology and environment that a firm competes. Companies should use the components of this framework in differing ways emphasizing different dimensions, often finding their own way of measuring success and at times in conflict with these guidelines. We believe, however, that the DMDS model provides a fair base with which to start the journey of success assessment.

\section{The Project Level}

Projects are launched today for a myriad of reasons: to develop new products, to establish manufacturing processes, to construct buildings, or to upgrade existing products. However, no matter what the motivation for the project, the 
FINANCIAL PERSPECTIVE

CUSTOMER PERSPECTIVE

PROCESS PERSPECTIVE

LEARNING PERSPECTIVE
FINANCIAL

MARKET/ CUSTOMER

PROCESS

PEOPLE

PREPARING THE FUTURE

Fig. (1). Comparison of the balanced scorecard to the DMDS.

Table 1. Overview of "Success Dimensions" Model

\begin{tabular}{|c|c|c|c|c|c|}
\hline Success Dimension & $\mathbf{1}$ & $\mathbf{2}$ & $\mathbf{3}$ & $\mathbf{4}$ & $\mathbf{5}$ \\
\hline Time Horizon & Very Short & Short & Mid-term & Long & \\
\hline Organization Level & & & & & \\
\hline Project & Project efficiency & Team Leadership/People skills & Impact on Customer & Direct business success & Preparing the future \\
\hline Corporate & Financial Performance & Market/Customer & Process & Human Capital & Creating the Future \\
\hline
\end{tabular}

question of assessing the project success has always been controversial and dependent on the assessor's point of view. One of the most common approaches to project success is to consider a project as successful for achieving its budget, schedule, and scope goals. Although this may seem appropriate in the short term, it is hardly sufficient. Quite often, what seemed to be a troubled project, with extensive delays and cost overruns, turned out to be a great business success. Consider, for example, Microsoft's Windows operating system development. When Microsoft launched its first Windows system it suffered substantial delays and required a continuous flow of resources and additional people. Yet, from the moment of introduction, it became an enormous source of revenue for the company and today more than $90 \%$ of all PCs utilize the Windows system. Similarly, just look at the extensive delay in Boeing's 787 Dreamliner development program. Boeing has no intention of canceling the 787 in spite of all the difficulties; Boeing will eventually fix the problems and in the end, the 787 will most likely be a profitable product.

Projects are powerful and efficient weapons, which are initiated to create economic value and competitive advantage for the organization. Therefore projects should be managed as strategic endeavors, not just as operational activities, be focused on achieving business results and winning in the market place [22]. Project management and teams have to spend a great deal of their time and attention on activities and decisions that will improve business position in the long run. Project managers are becoming the new strategic leaders, who take-on total responsibility for project business results. In today's rapid changing world, there is no time to share this responsibility in the old way, where project managers were concerned with "getting the job done," while other managers are responsible for business aspects. One can no longer distinguish between project success and product success; it is all part of the same game. Projects can no longer be seen as just operational tools for executing strategy, but rather the engines, and the drivers of strategy into new directions.

In our previous research we have already taken the first step toward the creation of a multidimensional framework for assessing project success [23]. In this paper we present the results of our later study which had two major goals, the first was to verify our assertion that the people dimension is as critical to projects as it is for corporations, and second to explore the measures comprising this human capital dimension.

We therefore returned to the original data and examined the factor analysis from a different point of view emphasizing the human capital aspect. (See Appendix A for a more detailed description of our factor analysis process). The results clearly showed that the human factor is a separate factor and not only a set of measures that belong to the fourth factor, preparing for the future. Our major findings are summarized in Table $\mathbf{2}$.

\section{Project Efficiency}

The first dimension is the short-term measure expressing the efficiency with which the project has been managed. It 
simply tells us how well the project met its initial specifications. Was it completed on time? And was it finished within the specified budget? Although meeting time and budget constraints may indicate a well-managed, efficient project, it may prove that this project is successful in the short-term but does not indicate that the organization and customers have benefited in the longer term.

Table 2. Typical Project Success Measures

\begin{tabular}{|c|c|}
\hline Success Dimension & Specific Typical Measures \\
\hline 1. Project Efficiency & $\begin{array}{ll}\text { - } & \text { Meeting time goal } \\
\text { - } & \text { Meeting budget goal }\end{array}$ \\
\hline 2. Team Leadership & $\begin{array}{l}\text { - } \text { Learning and Enrichment } \\
\text { - } \text { Team motivation } \\
\text { - } \text { Team morale } \\
\text { - Collaboration } \\
\text { - } \quad \text { Trust }\end{array}$ \\
\hline 3. Impact on the Customer & $\begin{array}{l}\text { - } \text { Project Vision } \\
\text { - } \text { Meeting functional performance } \\
\text { - } \text { The customer is using the } \\
\text { - } \text { product } \\
\text { - } \text { Fulfilling customer needs } \\
\text { - Customer satisfaction } \\
\text { Customer loyalty }\end{array}$ \\
\hline 4. Business and Direct Success & $\begin{array}{l}\text { - } \text { Commercial success } \\
\text { - } \text { Sales and profits } \\
\text { - } \text { Project net present value } \\
\text { - } \quad \text { Market share of Product } \\
\text { - } \quad \text { Business improvement }\end{array}$ \\
\hline 5. Preparing for the Future & $\begin{array}{ll}\text { - } & \text { Creating a new market } \\
\text { - } & \text { Creating a new product line } \\
\text { - } & \text { Developing a new technology } \\
\text { - } & \text { Building new infrastructure } \\
\text { - } & \text { Developing new skills }\end{array}$ \\
\hline
\end{tabular}

On the other hand, with increased competition and shorter product life cycles, time to market becomes a critical competitive component and therefore, enhanced project efficiency should be seen as adding to product competitiveness. Some organizations may find it beneficial to consider additional measures of efficiency. For example, cost of materials and tooling, efficiency and yield of production ramp, efficiency of purchasing, safety measures, etc. However, one must realize that all of these measures only relate to successful implementation of project execution and do not necessarily mean product success.

\section{Team Leadership}

This is the project's "people management" dimension. It clearly represents the investment, commitment and skills of the project manager in leading, organizing, and motivating the team members. But it also represents the team's "spirit" - the internal culture that was developed among team members, the collaboration, support, and joint effort, and of course the excitement and energy that often characterizes great projects. Project spirit is nurtured by creating a vision, and cultivating the values, the norms of behavior, the team internal interaction and mutual support and the social bonding of team members (Shenhar, 2004). Another aspect of the human capital management is the accumulation of knowledge through projects. Knowledge is one of the most important resources of the organization and projects are main vehicle for organizational learning.

The importance of team leadership on project success has received significant interest in recent years. Turner and Muller [24] provided a wide-ranging literature review on leadership style as a success factor on project success. For large capital projects, project leadership was one of the strong predictors of success [25]. Most interestingly, a few studies have indicated a mixed result on project performance. For example, Belout and Gauvreau [26] while finding a link between the personnel factor and project success (non-significant) they have indicated that this link does exist according to life cycle stage. The industry, project complexity and the age and nationality of the project manager also effect project success [27].

\section{Impact on the Customer}

The third dimension relates to the customer. This dimension addresses the importance one should place to the customers' requirements, and to meeting their needs. Understanding the "real" needs of the customer is extremely important and reflects the basic notion of success. From the developer's point of view, this dimension also includes the level of customer satisfaction, the extent to which the customer is using the product, and whether the customer is willing to come back for another project or for the next generation of the same product. A study on the relative importance of success dimensions has found that project managers perceive this dimension far more important than the other success dimensions [15].

\section{Business and Direct Success}

The fourth dimension addresses the immediate and direct impact the project may have on the developing organization. In the business context, did it provide sales, income, and profits as expected? Did it help increase business results and gain market share? Most important, did the project produce enough return on investment, and did it result in a positive cash flow?

This dimension may also apply to projects not aimed at building new products, but to internal organizational projects or to non-profit organizations. For example, organizations may need to assess the success of their re-engineering projects, or the building of new manufacturing processes. It will include measures of performance time, cycle time, yield, and quality of the process; all of them will assess the direct impact that the project had on the organization.

\section{Preparing for the Future}

The fifth dimension addresses the issue of helping prepare the organizational, operational and technological infrastructure for the future. How did the project contribute to future businesses and additional innovations? Did it produce a new technology? Did it create a new product line? And did it create a new market? Did we also build during this project new skills that may be needed in the future? Did we develop enough core competencies to be used later across different business lines? 


\section{Project Success Over Time}

Project success, therefore, should be considered as a dynamic concept, with different dimensions playing a role at different times, and their relative importance change with time. It also changes with project type [15]. As for time, the first dimension can be assessed in the very short to shortterm, during project execution and right after project completion. The second dimension, people leadership, is probably the most important dimension during project execution, but the results of creating a unified project team have also an enormous impact on the whole organization creating opportunities for the future. The third dimension (Impact on the Customer) is assessed after the project's product has been delivered to the customer, and the customer starts using it. The fourth dimension, business success, can be assessed after reaching a significant level of sales or after the brake-even point. Depending on the industry, this may usually take up to several years. While the fifth dimension can usually be assessed in the long term - several years may pass before this dimension can be fully exploited and judged. Notice that the people dimension manifests itself during the project as well as after completion, when the project team members are assigned to new projects and continue to exploit their experience and knowledge gained during previous projects.

\section{The Corporate Level}

A corporation is a diversified organization whose main goal is to create and increase value. While, the financial performance of the corporation is an indication of success in the short run, the corporation cannot succeed unless it adds value to the business by providing tangible benefits that offset the costs of overhead and lost independence. The ability to transfer competitive skills across businesses and use them to gaining company advantage over competitors is expressed by the core competency concept, representing the sum of learning across individual organizational units [1]. The corporation's effectiveness depends; therefore, on integrative decisions and activities that cross business boundaries, some of them having an immediate impact and others, whose impact can be recognized only in the longterm. The success in achieving synergy by operating as a unified company has to be measured from several vantage points. On one hand, it has to reflect the company's shortterm (financial) performance, and on the other hand, its success in creating an atmosphere of cooperation between the various business units, exploiting capabilities and core competencies across business boundaries, and establishing the vision, direction, and foundations for the future.

Our research at the corporate level [23] of 180 U.S. firms have resulted in the following five dimensions (see Table 1):

\section{Financial Performance}

This is the standard, traditional shortest-term dimension of organizational success. It reflects last quarter results such as sales, profit margin, and revenue growth. These indicators are based on sales from existing products and services, which are the result of strategic decisions made years ago. In some ways it can be argued that shareholder value (a financial perspective measure), may also represent a more long-term perspective, reflecting perceptions of future financial earnings. However, while missing one quarter's earning may significantly affect value, our later "future" dimension is truly a more complete representation of the long-term view.

\section{Market/Customer}

This dimension reflects the impact that the company has made on customers and markets, based on a cumulative effect of its strategic decisions. Key measures in this dimension include customer satisfaction index, customer retention rate and service quality, as well as company's reputation and image.

\section{Processes}

This dimension represents the success to achieve competitive advantage with the company's internal processes. It involves the company's set of core competencies developed during recent years in various businesses; and its ability to deliver these competencies to its different collection of businesses while exploiting them as fundamental customer benefits. The most frequently selected process measures included 'time to market for new products and services', 'quality of new product development and project management processes', 'quantity and depth of standardized processes', 'quality of manufacturing processes', and 'quality of innovation processes'.

\section{Human Capital (People and Leadership)}

A significant level of academic scholarship has linked the management of the firm's human resources to performance, highlighting the criticality of a 'People Development' dimension. A pragmatic summary of the importance of human resources is provided by Youndt et al. [28] who claim that, "The effective management of human capital, not physical capital, may be the ultimate determinant of organizational performance." Specific measures that were found significant in this dimension include 'retention of top employees', 'quality of professional/technical development', 'quality of leadership development', 'encourage employees to suggest and test new ideas' and 'employee skills training'. Recent studies support our basic assertion about the relationship between firm performance and human resource management [29, 30].

\section{Creating the Future}

This last and longest-range dimension is aimed at assessing the company's initiatives taken to create a new future for the company and its ability to create new trends in the industry. It involves its ability to see the future prior to competitors and customers, and to define new needs no one has articulated before. Within this dimension the company should strive to write the rules in its industry and define its insight. It must have the foresight to do things others will copy later and find new customers and needs not currently addressed. It should try and make a difference to customers by exceeding their expectations, by creating unimagined products, and by making the future real and tangible to customers and competitors.

Several measures could be utilized for assessing the corporate success along this dimension. For example, does the company's opportunity horizon extend beyond existing product markets? Is there sufficient investment in new 
technologies? Is there an explicit process for identifying and exploiting new opportunities beyond the boundaries of existing business units? Are these processes identifying new and unarticulated needs for existing and new customers, which are not served at the moment?

\section{Analyzing the Performance of Five U.S. Corporations with the DMDS Model}

To demonstrate the effectiveness of the multidimensional dynamic framework and its ability to address longer-term business concerns, we have included in Fig. (2) the relative ranking of five companies. We have selected these cases out of the 76 public companies in our study, since each demonstrates a unique angle of success with it own interesting 'story.'

Company $\boldsymbol{a}$ is a software services provider. It fared rather poorly across four of the five dimensions. One of its major businesses has collapsed during the time of this research as a result of an invasion of new technology. Its financial positions as well as future prospects looked weak. In fact, with its stock price so low, the company's management considered going private as a way of reducing expenses.

Company $\boldsymbol{b}$ is a successful licensed clothing manufacturer with high relative rankings in all dimensions except the 'Customer'. At the time of the survey they perceived some issues with a major customer, which has since been resolved. Their processes, people and future measures were strong. The company was sold with its stock price increasing more than $350 \%$ over three years.

Company $c$ is a major engineering firm with relatively poor rankings in all dimensions. It has endured major reductions in staff over many years, and has then replaced its CEO with an outsider. This company is in survival mode.

Company $\boldsymbol{d}$ is a leading financial services organization with high rankings in all dimensions. They are a leader in developing new products and understand their customers and markets; they are building a future.

Finally, company $\boldsymbol{e}$ serves a unique niche in the global technology market. Although their short-term financial ranking were low (they were investing for the future), their longer-term rankings were very high. As a result of their future potential, this relatively new company was acquired for a very significant price.

As mentioned, we are not arguing in this paper that the model is prescriptive for all industries, but suggest that these baseline measures can be applied to most organizations [23].

\section{Lessons Learned from Integrating the Project and Corporate Levels}

In sum, the ability to measure a firm performance is critical to the firm's survivability and ensuring that a firm is also managed efficiently. While universal prescriptions do not apply, the DMDS provides sufficient guidance to management as a starting point in the process of developing actionable, success metrics to address areas of weakness. The following discussion summarizes our lessons from studying the two organizational levels.

\section{The Critical Role of the Human Capital}

There is no question that the human element has a critical role in the success and competitiveness of the modern organization. This becomes even more important with the acceleration of knowledge creation and the increased reliance of companies on knowledge management, knowledge assets and intellectual property (Nonaka, 2009). The temporal aspects within the project-driven organization have exacerbated the importance of managing resources across the organization. This suggests a need for a somewhat different focus than the classical product or process driven organization.

Indeed, many authors have emphasized the importance of the human element to the success of today's organization. For example, Ittner and Larcker [31] view human resource management practices as one of the key elements of process based performance improvements. They suggest that a firm's management and its employees can affect its financial performance as well as provide a valuable source of competitive advantage [29]. Similarly, Edvinsson and Malone [5] claim that "without a successful human dimension to a company, none of the rest of the value creations activities will work". Furthermore, organizations in the Silicon Valley have coined the term "wetware" representing the human input into economic activities; this

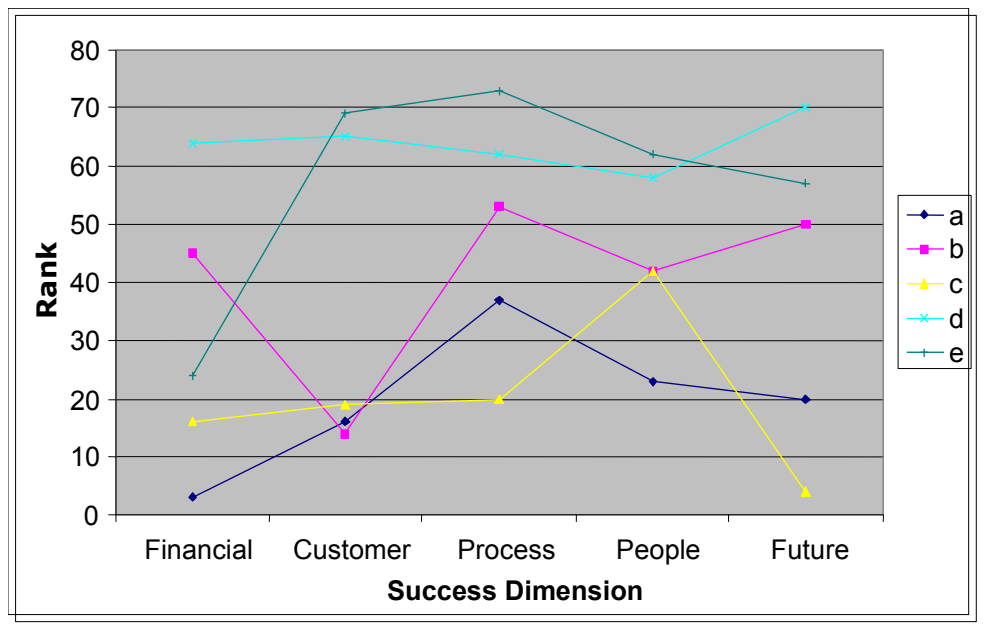

Fig. (2). Corporate level success dimensions. 
human activity can never be "owned", only "rented," and it is critical to any firms' success [32]. Project- oriented organizations have unique human resource management issues [33], they are better at providing organizations with competent people, but do not do as well at caring for their employees; many of these companies realizing the critical need for these people are providing career development opportunities to improve morale. Lastly, firms have embraced the notion of human capital as a competitive advantage that enhances higher performance [34].

In our study of success dimensions across two organizational levels, we have witnessed the importance of human capital again and again. Almost every manager that we interviewed has stressed the importance of human resources to the success of his or her company. Statements that we heard included the following quotes: a chairman of an engineering services firm asked: "Is staff morale higher than last period? This is critical to our success." A defense contractor president suggested that, "The morale of employees is very important. Unhappy employees will affect product quality, customer satisfaction and sales and profitability." And a general manager of a telecommunication equipment manufacturer said, "Employee skills, talent, and experience are the primary differentiator for high-tech firms today." When we looked at specific dimensions in our research at the corporate level, we found that 'retention of top employees' was the second most frequently cited measure among all measures (second only to sales). It was rated as important or very important by $76.7 \%$ of all respondents.

The critical role of human capital at the project level is also evident in previous documented cases. As John Sculley put it in his book the Odyssey [35], "Steve (Jobs) provided phenomenal inspiration and demanding standards to get his team to do such things. He pushed them to their limits, until even they were amazed at how much they were able to accomplish. He possessed an innate sense of knowing exactly how to extract the best from people." (p. 164). To encourage and motivate his team, Jobs often held parties and weekend retreats for his team. He presented medals to his people, and rewarded good work with Apple stock options. He praised them, and rewarded the team when they moved to the Apple headquarters, by investing $\$ 1$ million on a lavish decor for the new Macintosh office. He also rewarded them by insisting that their names be inscribed on the inside of the Macintosh case. Steve Jobs has continued the same approach of motivating his people and pushing them to their limits until his last days at Apple a few weeks before his death [36]. ${ }^{1}$

For the development of the AS/400, IBM needed a leader, someone who would carry out this immense task. They found one in Tom Furey, Director of IBM's Rochester Development Laboratory [37]. Furey was able to create change; instead of moving the organization ahead in increments, he renewed and transformed it. Out of what he saw there emerged a vision-that a standard setting computer could be produced and, even more, that the Rochester team could become the model of transformation for all of IBM.

${ }^{1}$ See also Fred Vogelstein's story on the development of the iPhone, in Wired Magazine, 16.02, 2008
He communicated his vision by giving it a careful articulation. He listened. He heard. He unleashed the talent. He wasn't afraid to accept blame or own up to mistakes. "You're right, we screwed up," he'd declare. When his guests saw they could open up without risking repudiation, the meetings flourished, blooming into substantive exchanges. Furey drew people even more for his own talent for asking probing, but well meaning questions. People seemed captivated by his intellectual curiosity and his sincere interest in what they had to say.

Important enough, while it is evident that Human Capital is critical to the success of projects and corporations, shortcomings in people skills can cause the opposite effect, as the following case suggests: John De Lorean was considered an effective leader, but his actions eventually weakened his organization [38]. As the founder of the company, he lived an extravagant life. He flew the Concorde on his business trips, and insisted to be met at the airport as he did during his reign as a General Motors executive. Morale was weakened by loss of leadership. This style accelerated the disintegration of upper management, and as a result, it became a strong barrier to the project team performance.

So, why is it that when it comes to actual measurements, only a few organizations were found to be using a formal explicit method to assess the company's success in treating its employees, employee morale and satisfaction, or skills and productivity? The conclusion is clear: adding the assessment of the human element as an indicator for performance may be critical to short-term success, but more important, to an organization's long-term success. It may also serve as a pre-warning for trouble. For example, if a growing number of people are leaving and turnover is increasing, clearly, something is wrong, either in vision, strategy, allocating resources, culture, or even leadership in general.

Integrating the results of our studies, we concluded, that the human element could indeed be measured. Furthermore, while different people issues should be looked-at different organizational levels, there is a common element across all organizational levels that should be measured in order to guarantee sustainable success in the long run. The human element at the project or team level should be focused on team leadership, team morale, and team spirit, and on the ability to learn and accumulate project related knowledge. An individual project is a temporary organization that only exists as long as the work toward the project goal continues. When the goal has been reached, the project ends and team members are assigned to other projects or commitments, bringing with them the experience and knowledge they have gained through the project's life cycle. Thus the short-lived nature of projects suggests that dealing with people on a project should be focused on creating the immediate motivation and spirit that is needed to get the job done, but also retaining that spirit and experience for future projects. Great project teams are characterized by high team spirit, extensive morale, and mutual support among team members. Leaders of great projects are distinguished by their ability to make the team function as one, to support team members in their personal issues, and create a unity and community among team members so that they will feel that they are part 
of a unique excellent team. Typical measures at the project level may include how people feel about being part of this team, how proud they are to be on the team, how much they are supported by their peers, and how much are they challenged by the goals and tasks of their project and what have they gained that will stay with them in future assignments.

At the corporate level, the human capital management should be focused on longer-term issues. One of the most important issues is retention of top employees and professional workers. Another one would be the organizational culture and how well it supports the creativity, the innovation, or the quality of the customerfocus that the organization is trying to achieve. Yet another issue may be the quality of developing leadership skills and growing people to prepare better for their next assignments on a long-term basis. One may also include tracking company statistics on investment in professional training, development of employees' leadership and managerial capabilities.

\section{Preparing for the Future}

Just as the human issue extends as important throughout the spectrum of organizational levels, preparing for the future appears a common theme at the corporate, as well as the project level. This measure emerged from previous frameworks, which dealt with learning or investments in R\&D. Naturally, this is the longest-term dimension, and success in preparing for the future is perhaps the most important dimension for sustainable on-going success. Yet short-term pressures are often preventing organizations from investing in the future or even assessing the way they are operating for achieving sustainable success.

Our multi-level studies have shown that this issue is in fact on many managers' minds, yet when implementing a formal framework for measuring success, only a few organizations make this dimension part of their assessments structure. Here too, we found different specific measures may be relevant for the dimension of preparing for the future. Starting with the project level, preparing for the future means that the project is being managed to achieve more than just immediate business and profit related goals. If projects are well managed with the organization long-term business goals in mind, beside meeting the immediate project goals, resources are also invested in developing new technologies or preparing infrastructures and capabilities that would be used in the future for other projects and by other product lines. Another aspect of preparing for the future is creating new opportunities in the market place, either serving underserved needs in existing markets, or developing new markets with untapped potential for existing and new products. Typical measures include developing new technologies, the extent of creating new markets and developing new organizational capabilities.

At the corporate level, what is important for the future is the ability of the company to create leadership in the industry, to define the foresight for the future of the industry, and to invest in creating new businesses while identifying opportunities that are outside of the territory of existing businesses. The corporation should also assess its total investment in $R \& D$, in creating partnerships with potential allied companies, and its investment in infrastructure such as IT, global markets, and international outreach.

Finally, one may argue a distinction between "preparing for the future" and "preparing the future" as part of a causation argument (Weick, 2001; Logman, 2011). Based on our interviews, we selected to look at both as the same dimension representing the "future perspective" of an organization success. In reality when managers prepare the future they see themselves also as preparing for the future. In real organizational cases, however, companies will select their own measures in any specific case.

\section{IMPLICATIONS AND CONCLUSION}

Since 'projects are temporary endeavors,' the temporal aspect of the success dimensions clearly signifies the need to integrate the project and corporate levels. Organizations seeking to leverage individual projects must have effective capabilities in managing critical human resources between projects to gain synergies. This distinction was not always recognized by the prior literature and not taken into account when building frameworks for assessing success of projects and entire firms. The difference of impact in time on each dimension must clearly affect the way such endeavors are managed.

Building a strong infrastructure that supports the ongoing activities of the enterprise has to be done holistically, from the top management level, providing the vision, formulating the strategy and allocating resources to the different business units, in line with the approved strategy (Barnard, 1951). At the same time it has to come from the operational level, mainly from the project level, where new initiatives are converting vision and ideas into products. This study has shown that top-level management's vision must be translated to specific goals and measures at the project and team levels. By better understanding the overall organizational goals and by being required to achieve specific business related goals, project teams will be better equipped to do their job both effectively as well as efficiently. Addressing specific dimensions at the project level will add an important component to the planning, execution and monitoring of the organization's operations and help prepare it better to future growth and profitability.

In conclusion, perhaps the need for a new dynamic framework can be best described by observations from the corporate literature. As mentioned, Hamel and Prahalad [1] defined a new view of corporate strategy. Their premise is that competition for the future will be to create and dominate emerging opportunities - to stake out new competitive space. Companies that are too focused on today's issues and not preparing for the future will simply not survive. And Collins and Porras [39] and Collins (2001) emphasized that one of the fundamental attributes of organizations that have endured for years are the "envisioned future." They specifically define this term as setting a "big hairy audacious goal" that truly stretch an organization's resolve and resources and has the potential to shape the future. This may take the firm from ten to thirty years to achieve-a long period of corporate life, and clearly indicates the need for long-term success assessment methods.

The "Dynamic Multidimensional Success Model" provides a practical framework for organizational 
performance assessment. It looks at the organization as a "whole' from the project level to the corporate level and gives managers a practical starting point for effectiveness measures over multiple timeframes. The appropriate set of measures depends on the firm's strategy, technology, and the particular industry and environment that a firm competes.

\section{ACKNOWLEDGEMENT}

Declared none.

\section{CONFLICT OF INTEREST}

The author(s) confirm that this article content has no conflicts of interest.

\section{APPENDIX A- NOTE ON PROJECT LEVEL RESEARCH METHODOLOGY}

As described in the text, we chose to perform a two-stage study, which involved a combination of qualitative and quantitative methods and two data sets. The first stage involved a case study research on 15 projects and the second a statistical analysis study on 127 projects. The fifteen case study projects were part of the larger sample of 127 projects, which seem to add only an insignificant bias to our findings.

All projects we studied were either completed within the recent year, or they were in their last quarter before completion. Data collection was performed in Israel, in the mid 1990s, in firms operating in the military, or the commercial market. The projects studied were in a wide variety of industries (e.g., electronics, aerospace, computers, chemical), had significant range in budget (from $\$ 40,000$ to $\$ 2.5 \mathrm{~B}$ ), project duration (from 3 months to 12 years), markets served, and project purpose.

Caution should be exercised in generalizing the results of this study, since the projects studied here were not randomly selected and may not be representative of all projects in general, or in other parts of the world. However, Israeli industry is closely coupled to Western culture, either in Europe or the US; many of the organizations involved in our study are subsidiaries or partners of American companies, and there is no reason to suspect that the study was biased in any significant way.

Data collection for the first part (case study) was multifaceted, and included in-depth interviews, which were conducted by teams of two or three, and involved at least three people from each project. In addition to the project managers, we interviewed members of the project management team, functional team members that were involved in the project, project managers' supervisors, and customer representatives. To strengthen our research validity, and as is often required by qualitative studies, we insisted that investigators interact with their subjects on their own turf, namely at the project site

Interviews involved open questions on the project mission and objectives, the motivation and the expectations from the project of the different parties involved: the contractor, customer, and user. Data were also obtained on success of the project, as perceived by the different parties, and as compared to their initial expectations. Finally, we obtained data on specific goals and achievements such as meeting time and budget goals, meeting technical and functional requirements, fulfilling customer needs, and achieving various business-related results.

The qualitative case data of this study were processed through a method of cross-case comparative analysis, and as required by this method, it was highly iterative, with continuous comparison of data and theory. This method as described by Eisenhardt [40] (p. 533) "forces investigators to look beyond initial impressions and see evidence through multiple lenses."

During the case study part of our study, and based on the experience gained in previous studies, we prepared a list of thirteen specific measures to account for the interests of various parties (see the right side of Table 2). This list formed the basis for the structured questionnaire, which was used during the quantitative part. During this phase, respondents were asked to rate the importance they place to each of these measures on a seven-point assessment scale, from "very low" to "very high." They were also asked to use a seven-point scale to rate the degree of success they perceived in each of these thirteen measures, as well as in a fourteenth measure, which involved an assessment of the project overall success.

Data analysis in this part, involved calculating the descriptive statistics and Pearson Correlation coefficients between the fourteen measures we studied. We also performed a factor analysis on these measures to identify whether they can be clustered as groups of typical measures, which are strongly related to each other, and thus can be described as separate success dimensions.

\section{REFERENCES}

[1] Hamel G, Prahalad CK. Competing for the future. Boston: Harvard Business School Press 1994.

[2] Kaplan RS, Norton DP. The balanced scorecard - Measures that drive performance. Harv Bus Rev 1992; 69(1): 71-9.

[3] Atkinson AA, Waterhouse JH, Wells RB. A stakeholder approach to strategic performance measurement. Sloan Manage Rev 1997; 38(3): 25-37.

[4] Smith M. Measuring organizational effectiveness. Manag Account 1998; 76(9): 34-6.

[5] Edvinsson L, Malone MS. Intellectual capital. New York: Harper Collins 1997.

[6] Wu CR, Chin-Tsai L, Tsai PH. Analysing alternatives in financial services for wealth management banks: the analytic network process and the balanced scorecard approach. IMA J Manage Math 2009; 20: 303.

[7] Beard D. Successful applications of the balanced scorecard in higher education. J Educ Bus 2009; 84: 275.

[8] Naranjo- Gil D. Strategic performance in hospitals: The use of the balanced scorecard by nurse managers. Health Care Manage Rev 2009; 34: 161.

[9] Strecker L. Balanced scorecard at Best Foods. Presented at the SATM Roundtable. Hoboken, NJ 1999.

[10] Moon P, Fitzgerald L. Delivering the goods at TNT: the role of the performance measurement system. Manag Account Res 1996; 7: 431-57.

[11] PMI. A Guide to the Project Management Body of Knowledge. Newton Square, PA: Project Management Institute (PMI) 2009.

[12] Lim CS, Mohamed MZ. Criteria of project success: an exploratory re-examination. Int J Proj Manag 1999; 17: 243-8.

[13] Freeman M, Beale P. Measuring project success. Proj Manag J 1992; 1: 8-17.

[14] Cooper RG, Kleinschmidt EJ. New products: What separates winners from losers. J Prod Innov Manage 1987; 4:169-84.

[15] Shenhar AJ, Dvir D, Levy O, Maltz AC. Project success: A multidimensionsal strategic concept. Long Range Plann 2001; 34: 699-725. 
[16] Griffin A, Page AL. PDMA success measurement project: Recommended measures for product development success and failure. J Prod Innov Manage 1996;13: 478-96.

[17] Dvir D, Shenhar A. Measuring the success of technology-based strategic business units. Eng Manag J 1992; 4: 33-8.

[18] Brancato CK. New corporate performance measures. New York: The Conference Board 1995.

[19] Rogers GPH. Measuring International Product Development Performance. EIBA Conference, Athens, Greece 2002

[20] Otley DT. Management control in contemporary organizations: Towards a wider framework. Manag Account Res 1994; 5: 289-99.

[21] Kalagnanam SS. The use of nonfinancial performance measures and their relationship to strategy. Unpublished Ph.D. dissertation. Madison: The University of Wisconsin 1997.

[22] Shenhar A. Strategic project Leadership toward a strategic approach to project management. R D Manag 2004; 34: 569-78.

[23] Maltz AC, Shenhar AJ, Reilly RR. Beyond the balanced scorecard: Refining the search for organizational success measures. Long Range Plann 2003; 36: 187-204.

[24] Turner JR, Muller R. The project manager's leadership style as a success factor on projects: a literature review. Proj Manag J 2005; 3: 649 .

[25] Scott-Young C, Samson D. Project success and project team management: Evidence from capital projects in the process industries. J Operation Manag 2008; 26(6): 749-66.

[26] Belout A, Gauvreau C. Factors influencing project success: the impact of human resource management. Int J Proj Manag 2004; 22:

[27] Muller R, Turner R. The influence of project managers on project success criteria and project success by type of project. Eur Manag J 2007; 25: 298-309.
[28] Youndt MA, Snell SA, Dean JW, Lepak DP. Human resource management, manufacturing strategy, and firm performance. Acad Manage J 1996; 39: 836-66.

[29] Uysal G. Relationship among HR and firm performance: A Turkey context. J Am Acad Bus 2008;13: 77.

[30] Akdere M. A multi-level examination of quality-focused human resource practices and firm performance: evidence from the US healthcare industry. Int J Hum Resour Manag 2009; 20:1945.

[31] Ittner CD, Larcker DF. Product development cycle time and organizational performance. J Mark Res 1997; 34: 13-23.

[32] Lessard D. Bank of America roundtable on the soft revolution: Achieving growth by managing intangibles. J Appl Corp Finance 1998; 11: 8-27.

[33] Turner R, Huemann M, Keegan A. Human resource management in the project-oriented organization: Employee well-being and ethical treatment. Int J Proj Manag 2008; 26: 577.

[34] Marimuthu M, Arokiasamy L, Ismail M. Human capital development and its impact on firm performance: Evidence from developmental economics. J Int Soc Res 2009; 2: 265-72.

[35] Sculley J, Byrne J. Odyssey: Pepsi to Apple - a Journey of a Marketing Impresario. NY: Harper Collins Publishers 1987.

[36] Isaacson W. Steve Jobs. New York: Simon \& Schuster 2011.

[37] Bauer RA, Collar E, Tang V, Wind J, Houston PR. The Silverlake Project: Transformation at IBM. USA: Oxford University Press 1992.

[38] DeLorean JZ, Wright JP. On a Clear Day You Can See General Motors: John Z. DeLorean's Look Inside the Automotive Giant. NY: Smithmark Publishers 1979.

[39] Collins JC, Porras JI. Built to last. New York: Harper Collins 1994.

[40] Eisenhardt KM. Building theories from case study research. Acad Manage Rev 1989; 14: 532-50

(C) Maltz et al.; Licensee Bentham Open.

This is an open access article licensed under the terms of the Creative Commons Attribution Non-Commercial License (http://creativecommons.org/licenses/by$\mathrm{nc} / 3.0 /$ ) which permits unrestricted, non-commercial use, distribution and reproduction in any medium, provided the work is properly cited. 